\title{
Self-medication Practices and Knowledge among Lebanese Population: A Cross-sectional Study
}

\author{
Sanaa Awada ${ }^{(D)}$, Batoul Diab, Dalia Khachman, ${ }^{*}$, Rouba K. Zeidan ${ }^{(D)}$, Helene Slim, Salam Zein ${ }^{(D)}$ \\ Amal Al-Hajje, Jinan Kresht, Souheir Ballout, Samar Rachidi \\ Clinical and Epidemiological Research Laboratory, Faculty of Pharmacy, Lebanese University, Hadat, Lebanon
}

\section{ARTICLE INFO}

\section{Article History}

Received 10 December 2019

Accepted 25 April 2020

\section{Keywords}

Community pharmacy

knowledge

Lebanon

practice

self-medication

\begin{abstract}
Self-medication (SM), practiced globally, is an important public health problem. This is the first study aiming to determine the prevalence of inappropriate usage of drugs among Lebanese patients, assess their knowledge, and identify predicting factors of potentially inappropriate drug intake. This cross-sectional prospective survey was carried out in five Lebanese governorates. A structured interview was done with patients who visited pharmacies. Data were analyzed using SPSS version 21 (SPSS Inc., Chicago, IL, USA). A multivariate logistic regression was performed to investigate factors associated with SM, which was reported by $79.1 \%$ of 930 interviewed cases. The most common symptoms warranting SM were symptoms relating to ear, nose, and throat diseases (99.0\%), gastrointestinal symptoms including nausea and vomiting (75.6\%), and cold and flu symptoms (60.1\%). Age [adjusted odds ratio $(\mathrm{ORa})=1.44 ; 95 \%$ confidence interval $(\mathrm{CI}), 1.15-1.80 ; p=0.002$ ] and sex $(\mathrm{ORa}=1.60$; CI, 1.16-2.21; $p=0.004)$ significantly increased the odds of SM. Medication classes commonly consumed by respondents for SM included acetaminophen-based analgesics (48.7\%) and nonsteroidal anti-inflammatory drugs (24.6\%). Moreover, $83.7 \%$ of respondents thought they were knowledgeable about proper dosing of the self-medicated drug (in fact, only $69.0 \%$ had adequate knowledge), and $35.5 \%$ thought they knew about side effects (assessment showed only $59.5 \%$ of them were right). Our study shows that SM is common among Lebanese adults. Hence, reinforcement of laws is necessary to improve access to adequate health care; efforts are needed to increase patients' education regarding the health risk related to inappropriate consumption of medication.
\end{abstract}

() 2020 Dr. Sulaiman Al Habib Medical Group. Publishing services by Atlantis Press International B.V. This is an open access article distributed under the CC BY-NC 4.0 license (http://creativecommons.org/licenses/by-nc/4.0/).

\section{INTRODUCTION}

Medications represent an important remedy for most illnesses, and they ensure the amelioration of the quality of life of patients. However, inappropriate intake of these substances may be associated with health risks. Practicing Self-medication (SM) is troublesome because of the facilitated access to therapeutic drugs leading to potential risks on health [1]. Regulations generally differentiate between two drug categories. The first is prescription-only, which requires a medical prescription for these medications to be dispensed; the second group includes Over-the-counter (OTC) drugs, which are easier to access for SM for uncomplicated and treatable medical cases. Despite this distinction, numerous patients tend to self-medicate regardless of the type of drug listed-that is, even prescription-only medications are somehow accessible for them without a prescription [2].

According to the World Health Organization (WHO), SM is the "selection and use of pharmaceutical or medicinal products by the consumer to treat self-recognized disorders or symptoms, the intermittent or continued use of a medication previously prescribed by

"Corresponding author. Email: dalia.khachman@outlook.com

Peer review under responsibility of the Dr. Sulaiman Al Habib Medical Group Data availability statement: The data that support the findings of this study are available from the corresponding author, [D.K.], upon reasonable request. a physician for chronic or recurring disease or symptom, or the use of medication recommended by lay sources or health workers not entitled to prescribe medicine" [3]. The main sources of SM are relatives, friends, or pharmacists who not only provide medicines but also information about the use of these drugs [4]. Moreover, several factors-such as lack of access to health care, physician fees, time constraint, lack of trust in physicians, and inadequate implementation of drug laws-been shown to influence SM behavior [5].

Self-medication is commonly practiced in both developed and developing countries, but it is more common in the latter [6,7]. Drug misuse in the Middle East can be mainly attributed to the fact that prescriptiononly medications are dispensed without prescriptions [2]. Even though the SM issue had been covered in several studies, it has not yet received the attention it deserves; limited information has been available on its main determinants, particularly in developing countries. In fact, most studies on SM have been conducted in developed countries whose health care systems are dissimilar to ours in Lebanon.

To study what the population knows about a specific condition, how people behave in relation to it, and the factors affecting it, studies on knowledge and practices have been conducted worldwide. No studies performed in Lebanon have focused on the knowledge and practices related to use of medicines despite a high rate of SM, which has not yet been documented [8]. Thus, the objectives of our study were to (1) evaluate the knowledge and practices concerning medication, 
(2) identify the reasons for SM, (3) check the sources of information about medication, and (4) identify the potential factors that could influence SM practices among Lebanese patients.

\section{MATERIALS AND METHODS}

\subsection{Design and Study Population}

This cross-sectional prospective study was conducted in a communitybased pharmacy setting in Lebanon. During a 4-month period (February-June 2018), data were collected from Community Pharmacies (CPs) distributed in the five governorates of Lebanon: Beirut, South Lebanon, Mount Lebanon, Bekaa, and North Lebanon. Eligible participants were patients attending CPs who were interviewed face to face. The participants consisted of males and females aged 18 years or older visiting the pharmacies to get their medicines. Participants were distributed among two groups: those who practice SM versus those who do not. A voluntary informed consent was required for enrollment in the study.

\subsection{Sample Size Calculation}

Sample size $(N)$ calculation was performed using the formula: $N=4 P(1-P) /$ Precision $^{2}$. The reference prevalence of SM " $P$ " was taken as $87 \%$ as reported in a similar study conducted in Palestine [9]; the precision was fixed at 0.03 . This gave us a minimum sample size of 503 patients.

\subsection{Data Collection}

The study questionnaire was formulated in the official language (Arabic) and included four sections of 22 open-ended and four close-ended questions. For validation, it was pretested on 40 patients attending five pharmacies prior to the actual beginning of the study. This was to ensure that the questionnaire was fully comprehensible to the public. Data were collected by trained pharmacists who had been taught about the objectives and methods of the study. The first section of the questionnaire included questions on sociodemographic characteristics (age, sex, occupation, educational and marital status, employment status, salary, insurance, and lifestyle habits). The second section targeted information about the medical history of respondents, their chronic diseases, and the background medication. Respondents were also asked whether they practiced SM. The third section, which was exclusively applied to those who practiced SM, contained questions about respondents' reasons for SM, the pathological cause or symptoms inciting SM, and the source of information regarding their drug of choice. In the final section, the respondents who self-medicated were requested to answer questions examining their knowledge regarding the dosing regimen and side effects of one of the drugs used as an SM.

\subsection{Data Analysis}

Data entry and analysis were performed using SPSS version 21 (SPSS Inc., Chicago, IL, USA). Respondents were grouped into patients practicing SM and those who are not (Yes/No). Descriptive statistics were presented as frequencies and percentages of knowledge and practices. Chi-square test was done to check the differences between these two groups regarding their sociodemographic characteristics. A logistic regression analysis was performed to check for confounding variables and to calculate the odds ratios (OR) for independent ones for SM. Significance level was attained at $p \leq 0.05$.

\section{RESULTS}

\subsection{Baseline Characteristics}

A total of 930 adult patients were surveyed, of whom $52.2 \%$ were females. They were mainly young with a mean age of $37.5 \pm 15.2$ years (range, 18-82 years). The most common educational level was completion of elementary and high school education (49.0\%). Among participants, 79.1\% practiced SM, whereas 194 (20.9\%) did not (Table 1).

The characteristics of the study population and their SM behavior are illustrated in Table 1. The results show that SM was significantly more prevalent in females than in males (83.2\% vs. $74.7 \%$; $p=0.001)$. Similarly, young individuals $(p=0.003)$, and those with a university degree $(p=0.055)$ were more likely to administer SM than their counterparts. Finally, lack of insurance also appeared to be significantly related to SM practice $(p=0.049)$.

\subsection{Multivariate Analysis}

To check for the association between independent variables (sociodemographic and health-related factors) and the dependent variable (SM practice), we conducted a backward binary logistic regression, with all variables with $p \leq 0.2$ as the independent variables (see Table 1). Two variables show a significant association with the dependent variable: age [adjusted Odds Ratio $(\mathrm{ORa})=$ $1.44 ; p=0.002 ; 95 \%$ Confidence Interval (CI), 1.15-1.80] and sex $(\mathrm{ORa}=1.60 ; p=0.004 ; 95 \% \mathrm{CI}, 1.16-2.21)$. However, lack of insurance was shown to be a trend that might have an effect on SM in the future $(\mathrm{ORa}=2.09 ; p=0.057 ; 95 \% \mathrm{CI}, 0.98-4.48)$ (Table 2).

\subsection{Self-medication Practices among Participants}

Figure 1 shows that the most common indications for SM were associated with ENT (99.0\%) and Gastrointestinal (GI; 92.5\%) diseases. Our study showed a high percentage of nonprescribed obtainment of medicines to treat Ear, Nose, and Throat (ENT) illnesses (99\%), including flu/colds (60.1\%), followed by cough (54.7\%), and pharyngitis/laryngitis (52.5\%). As for GI diseases, the most common symptoms subjected to SM were nausea/vomiting (75.6\%), heartburn/gastroesophageal reflux (75.0\%), bloating (72.4\%), and diarrhea (69.9\%). In addition, SM was commonly practiced for lower respiratory tract infections such as bronchitis/pneumonia (52.3\%).

The classes of medicines commonly purchased by participants for SM were acetaminophen-based analgesics (48.7\%), Nonsteroidal Anti-inflammatory Drugs (NSAIDs) (24.6\%), and antibiotics (8.8\%). Moreover, the study identified patients' reasons for SM: the most common reason was that their illness was mild (45.1\%). 
Table 1 Characteristics of the study population

\begin{tabular}{|c|c|c|c|c|c|c|c|}
\hline \multirow[t]{2}{*}{ Characteristic } & \multicolumn{2}{|c|}{ All participants $(N=930)$} & \multicolumn{2}{|c|}{$\begin{array}{l}\text { Not practicing self- } \\
\text { medication }(N=194)\end{array}$} & \multicolumn{2}{|c|}{$\begin{array}{l}\text { Practicing self-medication } \\
\qquad(N=736)\end{array}$} & \multirow[t]{2}{*}{$p^{*}$} \\
\hline & $N$ & Percentage (\%) & $N$ & Percentage (\%) & $N$ & Percentage (\%) & \\
\hline Sex & & & & & & & 0.001 \\
\hline Male & 442 & 47.5 & 112 & 25.3 & 330 & 74.7 & \\
\hline Female & 488 & 52.5 & 82 & 16.8 & 406 & 83.2 & \\
\hline Age class (years) & & & & & & & 0.003 \\
\hline $18-39$ & 510 & 54.8 & 88 & 17.3 & 422 & 82.7 & \\
\hline $39-60$ & 321 & 34.5 & 75 & 23.4 & 246 & 76.6 & \\
\hline$\geq 60$ & 99 & 10.7 & 31 & 31.3 & 68 & 68.7 & \\
\hline Marital status & & & & & & & 0.23 \\
\hline Single & 414 & 44.5 & 79 & 19.1 & 335 & 80.9 & \\
\hline Married & 464 & 49.9 & 100 & 21.6 & 364 & 78.4 & \\
\hline Widowed or divorced & 52 & 5.6 & 15 & 28.8 & 37 & 71.2 & \\
\hline Region & & & & & & & 0.078 \\
\hline Beirut & 475 & 51.1 & 93 & 19.6 & 382 & 80.4 & \\
\hline North Lebanon & 21 & 2.3 & 0 & 0.0 & 21 & 100.0 & \\
\hline South Lebanon & 257 & 27.6 & 56 & 21.8 & 201 & 78.2 & \\
\hline Bekaa & 41 & 4.4 & 10 & 24.4 & 31 & 75.6 & \\
\hline Mount Lebanon & 136 & 14.6 & 35 & 25.7 & 101 & 74.3 & \\
\hline Educational level & & & & & & & 0.055 \\
\hline Illiterate & 43 & 4.6 & 8 & 18.6 & 35 & 81.4 & \\
\hline Elementary-High school & 456 & 49.0 & 110 & 24.1 & 346 & 75.9 & \\
\hline University degree & 431 & 46.4 & 76 & 17.6 & 355 & 82.4 & \\
\hline Work status & & & & & & & 0.701 \\
\hline Private sector employee & 278 & 29.8 & 59 & 21.2 & 219 & 78.8 & \\
\hline State or public employee & 166 & 17.8 & 37 & 22.3 & 129 & 77.7 & \\
\hline Self-employed & 142 & 15.3 & 32 & 22.5 & 110 & 77.5 & \\
\hline Unemployed & 68 & 7.4 & 17 & 25.0 & 51 & 75.0 & \\
\hline Housewife & 155 & 16.7 & 26 & 16.8 & 129 & 83.2 & \\
\hline Student & 121 & 13.0 & 23 & 19.0 & 98 & 81.0 & \\
\hline Salary range (USD) & & & & & & & 0.742 \\
\hline $0-500$ & 386 & 41.5 & 76 & 19.7 & 310 & 80.3 & \\
\hline $500-1000$ & 186 & 20.0 & 42 & 22.6 & 144 & 77.4 & \\
\hline $1000-1500$ & 208 & 22.4 & 47 & 22.6 & 161 & 77.4 & \\
\hline$\geq 1500$ & 150 & 16.1 & 29 & 19.3 & 121 & 80.7 & \\
\hline Insurance & & & & & & & 0.049 \\
\hline No & 69 & 7.4 & 8 & 11.6 & 61 & 88.4 & \\
\hline Yes & 861 & 92.6 & 186 & 21.6 & 675 & 78.4 & \\
\hline Type of insurance & & & & & & & 0.439 \\
\hline NSSC & 642 & 70.9 & 123 & 20.6 & 474 & 79.4 & \\
\hline Private insurance & 223 & 24.6 & 55 & 24.7 & 168 & 75.3 & \\
\hline Military health care insurance & 40 & 4.5 & 8 & 20.0 & 32 & 80.0 & \\
\hline Exercising & & & & & & & 0.199 \\
\hline No & 494 & 53.1 & 111 & 22.5 & 383 & 77.5 & \\
\hline Yes & 436 & 46.9 & 83 & 19.0 & 353 & 81.0 & \\
\hline Smoking status & & & & & & & 0.147 \\
\hline Nonsmoker & 389 & 41.8 & 90 & 23.1 & 299 & 76.9 & \\
\hline Smoker & 541 & 58.2 & 104 & 19.2 & 437 & 80.8 & \\
\hline Alcohol & & & & & & & 0.592 \\
\hline No & 515 & 55.4 & 103 & 20.0 & 412 & 80.0 & \\
\hline Yes & 380 & 40.8 & 85 & 22.4 & 295 & 77.6 & \\
\hline Occasionally & 35 & 3.8 & 6 & 17.1 & 29 & 82.9 & \\
\hline Chronic diseases & & & & & & & 0.679 \\
\hline No & 694 & 74.6 & 147 & 21.2 & 547 & 78.8 & \\
\hline Yes & 236 & 25.4 & 47 & 19.9 & 189 & 80 & \\
\hline Number of pathologies & & & & & & & 0.973 \\
\hline 1 & 197 & 83.8 & 41 & 20.8 & 156 & 79.2 & \\
\hline$\geq 2$ & 38 & 16.2 & 8 & 21.6 & 30 & 78.4 & \\
\hline
\end{tabular}

"The $p$ values obtained by Chi-square for categorical variable. All $p$ values $\leq 0.2$ are shown in bold. 
More than one-quarter of respondents $(26.1 \%)$ indicated that they self-medicated because they had tried the same medication previously and it was beneficial; $11.4 \%$ of self-medicated patients clarified that they did not have enough time to visit health care facilities. Some cited monetary constraints as the reason behind their SM (11.4\%). Another reason for SM was that a friend/relative was knowledgeable about the treatment for their conditions (6.0\%; Table 3).

Factors affecting the choice of medication were examined. Most respondents followed a pharmacist's advice $(36.9 \%)$ or a physician's advice (17.5\%). Others admitted their choice was based on a former prescription (23.8\%) or on an empty package of drug found at home (18.6\%). Patients who practiced SM were asked about the source of information for their medicines. The most common source was local pharmacists $(48.5 \%)$, followed by medicinal

Table 2 Characteristics associated with the use of self-medication ${ }^{\mathrm{a}, \mathrm{b}}$

\begin{tabular}{lcccc}
\hline \multirow{2}{*}{$\begin{array}{l}\text { Independent } \\
\text { variables }\end{array}$} & ORa & \multicolumn{2}{c}{$\mathbf{9 5 \% \text { Confidence interval }}$} & \multirow{2}{*}{$\boldsymbol{p}$} \\
\cline { 3 - 4 } & & Lower & Upper & \\
\hline Age class & 1.44 & 1.15 & 1.80 & 0.002 \\
Sex & 1.60 & 1.16 & 2.21 & 0.004 \\
Lack of & 2.09 & 0.98 & 4.48 & 0.057 \\
$\quad$ insurance & & & & \\
\hline
\end{tabular}

${ }^{a}$ Logistic regression backward stepwise likelihood ratio; Nagelkerke $R^{2}=0.040$; $p$-value for Hosmer-Lemeshow test $=0.960 ; p$-value of the omnibus test was $<0.001$.

bUnretained variables: region, educational level, smoking status, and exercising. leaflets (29.5\%) and physicians (12.4\%). The least common source of information was scientific books or journals, and the Internet (1.1\% each; Table 3$)$.

As shown in Figure 2, the knowledge assessment revealed that although $83.7 \%$ of the respondents thought they were knowledgeable about proper dosing regimen, only $69.0 \%$ of them had an adequate knowledge. Moreover, although 35.5\% thought they were knowledgeable about side effects, it was later confirmed that $40.5 \%$ of them had inadequate knowledge. A significant relationship was found between some sociodemographic characteristics of respondents and their medicinal knowledge. In fact, younger age and those who attended university had the highest levels of adequate knowledge regarding the proper dosage regimen $(74.2 \%$ and $74.4 \%$, respectively) as well as side effects $(67.6 \%$ and $65.9 \%$, respectively). The knowledge about side effects was also found to be significantly associated with marital status, work status, and source of information (Table 4).

\section{DISCUSSION}

The study has shown a high rate of SM (79.1\%), which was similar to the results of a study conducted among emergency departments of French academic hospitals, which showed that $84.4 \%$ admitted doing SM [10]. Our results indicate Lebanese women's willingness to self-medicate; this affirms the results of several studies [11-13], but contradicts others $[14,15]$. Similarly, younger respondents were using SM more often than their older counterparts, which comes

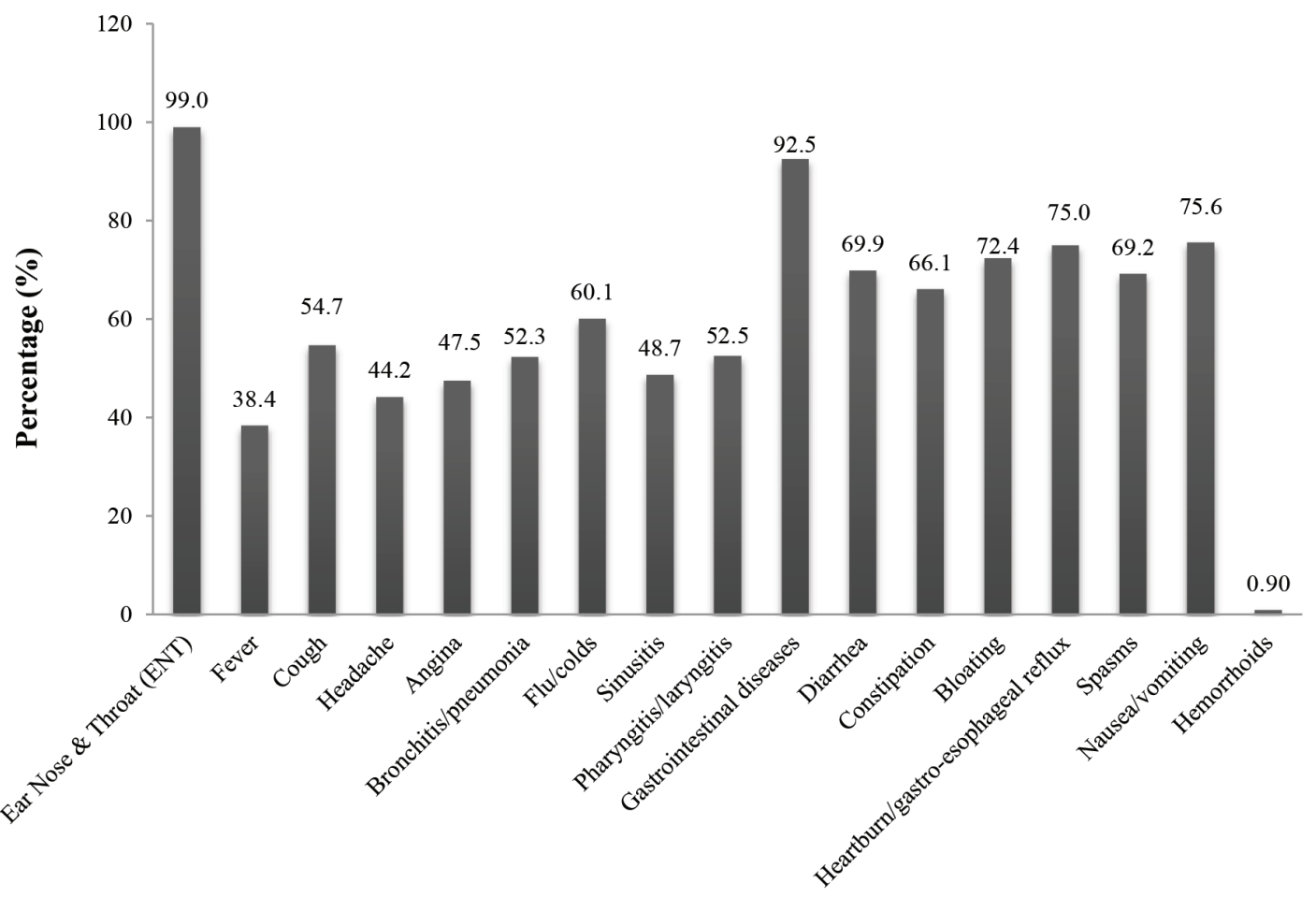

Symptoms

Figure 1 Symptoms warranting self-medication. Results are given in percentage. Numbers do not add up to $100 \%$ as patients might practice selfmedication for several illnesses. 
Table 3 Practices related to self-medication

\begin{tabular}{|c|c|c|}
\hline & $N$ & Percentage (\%) \\
\hline \multicolumn{3}{|l|}{$\begin{array}{l}\text { Classes of medicine used by respondents for } \\
\text { self-medication }\end{array}$} \\
\hline NSAIDs & 184 & 24.6 \\
\hline Antibiotics & 66 & 8.80 \\
\hline Antispasmodic drugs & 38 & 5.10 \\
\hline Sinusitis medications & 2 & 0.30 \\
\hline Acetaminophen-based analgesics & 364 & 48.7 \\
\hline GIT medicine & 53 & 7.10 \\
\hline Antiallergic medicine & 17 & 2.30 \\
\hline Vitamins & 23 & 3.10 \\
\hline Total & 747 & 100.0 \\
\hline \multicolumn{3}{|l|}{ Reason for practicing self-medication } \\
\hline Mild illness & 332 & 45.1 \\
\hline Lack of time & 84 & 11.4 \\
\hline Monetary constraints & 84 & 11.4 \\
\hline $\begin{array}{l}\text { According to the advice of a friend/ } \\
\text { relative }\end{array}$ & 44 & 6.00 \\
\hline Previous good experience with the drug & 192 & 26.1 \\
\hline Total & 736 & 100.0 \\
\hline \multicolumn{3}{|l|}{$\begin{array}{l}\text { Source helping in deciding which } \\
\text { drug to use }\end{array}$} \\
\hline Empty package of drug & 136 & 18.6 \\
\hline Former prescription & 174 & 23.8 \\
\hline Pharmacist's advice & 270 & 36.9 \\
\hline Physician's advice & 128 & 17.5 \\
\hline Others' advice & 23 & 3.20 \\
\hline Total & 731 & 100.0 \\
\hline \multicolumn{3}{|l|}{$\begin{array}{l}\text { Source of information of drugs for } \\
\text { self-medication }\end{array}$} \\
\hline Pharmacist & 357 & 48.5 \\
\hline Physician & 91 & 12.4 \\
\hline Package leaflet & 217 & 29.5 \\
\hline Scientific book or journal & 8 & 1.10 \\
\hline Internet & 8 & 1.10 \\
\hline Other & 55 & 7.50 \\
\hline$\underline{\text { Total }}$ & 736 & 100.0 \\
\hline
\end{tabular}

GIT, gastrointestinal tract; NSAIDs, nonsteroidal anti-inflammatory drugs. in concordance with the results of other studies [12-14]. Moreover, participants who were not insured were at risk of self-medicating. The misdistribution of health facilities and the accompanying increase in health care costs, which lead to the failure of a health care system, have been mentioned as a factor in SM [16]. It was also found that patients who have difficulty accessing health care services have a higher probability of becoming frequent users of SM in resolving their health problems [17]. SM is thus a phenomenon with vast social implications, especially in a developing country such as Lebanon where low income rates result in a high proportion of the population having trouble accessing the health care system. These results agreed with those of a Lebanese study showing a higher rate of antibiotic dispensation without a prescription in lower socioeconomic areas [18]. The educational level of participants appeared to be a significant factor in the bivariate analysis. Those with a university degree were more prone to self-medicate, as observed in other studies [19,20]; nevertheless, it was excluded from the logistic regression model, and this was also observed in a previous study [14].

Almost all self-medicators used SM for ailments associated with ENT and GI diseases, in concordance with the results of another study [15]. The most commonly self-medicated ENT illness was flu/cold; this has also been observed in several studies including a Spanish study, which found that $45 \%$ of cold and influenza treatments consumed by the population involve SM [16], and a study conducted by Badiger et al. [15], which revealed that $69 \%$ of conditions prompting SM were common colds. As for GI diseases, the most common symptoms subjected to SM were found to be nausea/vomiting, heartburn/gastroesophageal reflux, bloating, and diarrhea. This trend was similar to that seen in a Belgian study where the most dominant GI symptoms were burning retrosternal discomfort followed by acid regurgitation and bothersome postprandial fullness [21]. However, our results differ from a previous South Indian study that showed that the most reported GI symptoms were diarrhea (23\%), gastritis (21\%), and nausea/ vomiting (16\%) [15].

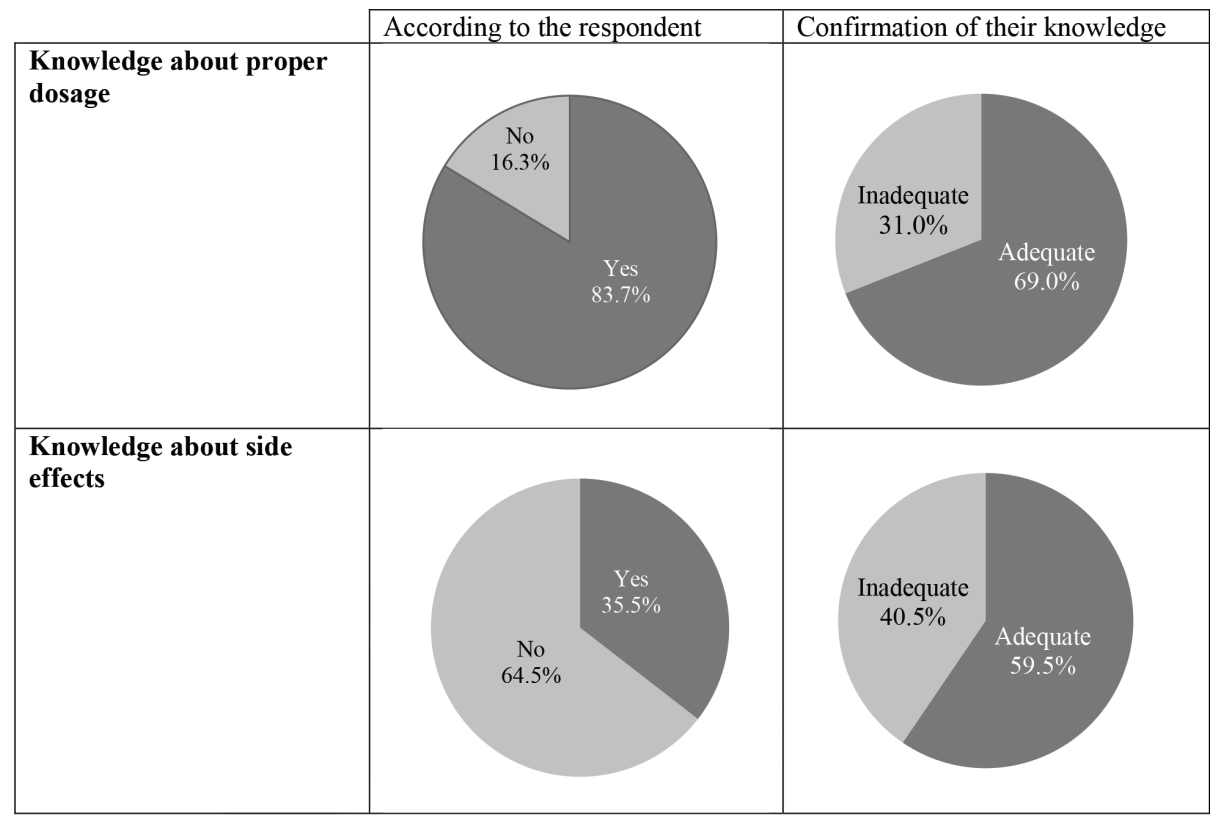

Figure 2 Medical knowledge of respondents. 
Table 4 Assessment of medicinal knowledge in patients practicing self-medication

\begin{tabular}{|c|c|c|c|c|c|c|}
\hline & \multicolumn{3}{|c|}{ Knowledge about proper dosage, $N(\%)$} & \multicolumn{3}{|c|}{ Knowledge about side effects, $N(\%)$} \\
\hline & $\begin{array}{c}\text { Adequate } \\
\text { knowledge }\end{array}$ & $\begin{array}{l}\text { Inadequate } \\
\text { knowledge }\end{array}$ & $p^{*}$ & $\begin{array}{c}\text { Adequate } \\
\text { knowledge }\end{array}$ & $\begin{array}{l}\text { Inadequate } \\
\text { knowledge }\end{array}$ & $p^{*}$ \\
\hline Age class (years) & & & 0.004 & & & 0.001 \\
\hline $18-39$ & $271(74.2)$ & $94(25.8)$ & & $115(67.6)$ & $55(32.4)$ & \\
\hline $39-60$ & $126(61.5)$ & $79(38.5)$ & & $38(45.8)$ & $45(54.2)$ & \\
\hline$\geq 60$ & $31(63.3)$ & $18(36.7)$ & & $5(38.5)$ & $8(61.5)$ & \\
\hline Marital status & & & 0.136 & & & 0.003 \\
\hline Single & $216(73.0)$ & $80(27.0)$ & & $92(69.2)$ & $41(30.8)$ & \\
\hline Married & $195(65.9)$ & $101(34.1)$ & & $60(48.4)$ & $64(51.6)$ & \\
\hline Widowed or divorced & $17(63.0)$ & $10(37.0)$ & & $6(66.7)$ & $3(33.3)$ & \\
\hline Education level & & & 0.020 & & & 0.015 \\
\hline Illiterate & $13(68.4)$ & $6(31.6)$ & & $2(33.3)$ & $4(66.7)$ & \\
\hline Elementary-High school & $191(63.9)$ & $108(36.1)$ & & $46(49.5)$ & $47(50.5)$ & \\
\hline University studies & $224(74.4)$ & $77(25.6)$ & & $110(65.9)$ & $57(34.1)$ & \\
\hline Work status & & & 0.097 & & & 0.001 \\
\hline Private sector employee & $137(69.2)$ & $61(30.8)$ & & $63(67.0)$ & $31(33.0)$ & \\
\hline State or public employee & $76(71.7)$ & $30(28.3)$ & & $19(39.6)$ & $29(60.4)$ & \\
\hline Self-employed & $59(64.8)$ & $32(35.2)$ & & $18(46.2)$ & $21(53.8)$ & \\
\hline Unemployed & $30(71.4)$ & $12(28.6)$ & & $8(88.9)$ & $1(11.1)$ & \\
\hline Housewife & $59(60.2)$ & $39(39.8)$ & & $14(45.2)$ & $17(54.8)$ & \\
\hline Student & $67(79.8)$ & $17(20.2)$ & & $36(80.0)$ & $9(20.0)$ & \\
\hline Insurance & & & 0.709 & & & 0.066 \\
\hline No & $30(66.7)$ & $15(33.3)$ & & $6(37.5)$ & $10(62.5)$ & \\
\hline Yes & $398(69.3)$ & $176(30.7)$ & & $152(60.8)$ & $98(39.2)$ & \\
\hline $\begin{array}{l}\text { Source of information of } \\
\text { drugs for self-medication }\end{array}$ & & & 0.678 & & & 0.035 \\
\hline Pharmacist & $197(68.6)$ & $90(31.4)$ & & $43(69.4)$ & $19(30.6)$ & \\
\hline Physician & $57(72.2)$ & $22(27.8)$ & & $20(71.4)$ & $8(28.6)$ & \\
\hline Package leaflet & $132(71.0)$ & $54(29.0)$ & & $79(57.2)$ & $59(42.8)$ & \\
\hline Scientific book or journal & $6(75.0)$ & $2(25.0)$ & & $3(75.0)$ & $1(25.0)$ & \\
\hline Internet & $4(50.0)$ & $4(50.0)$ & & $1(33.3)$ & $2(66.7)$ & \\
\hline Other & $32(62.7)$ & $19(37.3)$ & & $12(38.7)$ & 19 (61.3) & \\
\hline
\end{tabular}

"Statistically significant results are shown in bold. $p$ value detected by Pearson Chi-square test.

Concerning the families of drugs frequently taken by participants for SM, acetaminophen-based analgesics came in first place, NSAIDs second, followed by antibiotics. This trend resembles the findings of a Palestinian study, in which analgesics including NSAIDs (79.2\%), followed by flu medication (45.3\%), and antibiotics (33.0\%) were the most common classes of drugs used in SM [9].

However, our results differ from those of an Indian study, which showed that antipyretic (71\%), acetaminophen-based analgesics (65\%), antihistamines (37\%), and antibiotics (34\%) were the drug classes that were frequently used [15]. In fact, it is well known that acetaminophen-based analgesics are the most commonly used OTC class of drugs for SM [22,23], as the most frequent symptom for which drugs, without a medical prescription, are sought is pain $[11,23]$. This was followed by NSAIDs, which are a matter of concern because of their GI, cardiovascular, hepatic, and renal complications [24,25]. Moreover, attention should be focused on the antibiotic SM values reported in our study, because inadequate consumption of antibiotics could result in antibiotic resistance, one of the public health concerns particularly in developing countries [26].

The current study also identified patients' reasons for SM. The most commonly cited factor is mild illness, as found in the study of
Al-Ramahi [9]. In fact, it is generally acknowledged that SM has a significant role in the management of minor ailments [11,27]. Nearly one-quarter of respondents indicated that they self-medicated because they had already used the same medicine in the past and it was beneficial, whereas others self-medicated because they simply did not have enough time to visit health care facilities or because of consultation costs. Such reasons are consistent with those previously reported in different studies $[9,14]$.

Only $6 \%$ of the participants admitted that the reason why they self-medicated was that a friend or a relative recommended the drug. Our observations are comparable with those obtained in a study conducted in Chile, where only $6.4 \%$ of SM used was recommended by a family member and $4.1 \%$ by friends [11], but are in contrast with the results from a study performed by Badiger et al. [15], who found that $38 \%$ of medical students used their senior/ classmates as sources of information of SM.

We then examined the factors that influenced the choice of the drug used. In most cases, respondents followed a pharmacist's advice $(36.7 \%)$, whereas $17.4 \%$ based their decision on a physician's advice. Thus, we noticed that pharmacies have enabled SM, and have been acting as medication prescribers. This outcome is in line with other studies from neighboring countries including 
Saudi Arabia [14], Egypt [28], and Palestine [9]. Others admitted that their choice was based on an old prescription $(23.6 \%)$ or on an empty package of medication found at home (18.5\%). Indeed, multiple indications highlighted an association between SM and stocks of drugs at home [29], which could represent a risk source, especially if they are of a tight therapeutic margin, are expired, or could be accessed by children [30].

The most common source of information found in our sample was local pharmacists, reported by about half of the respondents, highlighting the utmost importance of pharmacists in minimizing SM risk within this population. This was followed by medicine leaflets, which should give information about the process itself; however, they could be misunderstood depending on the discrepancy between the reading level of the leaflet and the reading and comprehension skills of the patient. As a matter of fact, in our results, only $57.2 \%$ of those who thought themselves knowledgeable and using the leaflet as a source of information had an accurate knowledge about the side effects versus $32.6 \%$ of the examined group in India who were ignorant about the adverse effects of the drugs they used [15]; meanwhile, in a study conducted by Farah et al. [31], 76\% of the respondents knew the side effects of using unprescribed drugs. Next, came those who have physicians as a source of information (12.4\%); this small percentage is to be expected, because a lot of people think that doctors do not recommend SM [32], as many believe that doctors are usually reluctant to give patients advice on SM without a clinical examination.

The lesser used sources of information include scientific books or journals and the Internet. Other sources of information (7.5\%), which are probably unreliable ones, include relatives, friends, and the media, and people can readily be misled by these sources [33]. SM can be risky if used by poorly informed people. The knowledge regarding drugs used needs to be assessed, because of the variable level of patients' knowledge regarding their medications [34]. The knowledge assessment revealed that $83.7 \%$ and $35.5 \%$ of the respondents thought they were knowledgeable about proper dosing regimen and side effects, respectively, when in fact only $69.0 \%$ and $59.5 \%$ of them had an adequate knowledge. This constitutes an alarming finding, which shows that patients overestimate their knowledge about proper dosage. Moreover, this reveals that the overall population is not sufficiently experienced for practicing responsible SM, contrary to the WHO-advocated approach [35].

Our results showed that the medicine knowledge of respondents was significantly affected by some sociodemographic characteristics. In fact, younger people and those who attended university had the highest levels of adequate knowledge regarding the proper dosing regimen and the side effects of certain drugs. Knowledge about side effects was also found to be significantly associated with marital status, work status, and source of information. Concerning the latter, the highest percentage of accurate knowledge of adverse effects was found in scientific books or journals. Other sources were physicians followed by pharmacists, whereas the most likely source of misinformation was the Internet. Again, this finding highlights the importance of the community pharmacists' role, especially in view of their convenient position in the community to aid and guide a safe and efficient utilization of medicines, especially in the case of self-medicators [35].
Multiple limitations should be considered when interpreting the outcome of this study. First, the results of our study were obtained from self-reported data; hence, they may be subjective and respondents may be reluctant to answer truthfully questions relating to self-medicated utilization of certain drugs, because of the sociocultural habits that surround the consumption of certain drugs. Second, a recall bias might occur because no recall period was fixed, which may lead to a greater imprecision (especially underestimation) of prevalence estimates [36], and decreases the accuracy of recall. Nevertheless, it should be noted that the aim of this study was not to measure the prevalence of SM; had this been the case, a fixed recall period would have been mandatory. In fact, in cross-sectional studies, a prolonged recording period may be required in order to make the period more representative, especially when day-to-day variation is marked. However, this may be countervailed by less accurate reporting. Therefore, recall accuracy and representativeness ought to be well balanced. Another possible shortcoming may be that our sample was relatively young, possibly explaining the low chronic diseases rate found. This may have led to the underestimation of the effect of comorbid diseases on the practice of SM as several studies have shown a correlation between these two factors [14,20].

\section{CONCLUSION}

Our study represents a significant step forward in understanding the SM practices among Lebanese patients. The present study demonstrated a high level of SM practices but inadequate medicine knowledge among respondents. Hence, remedial actions are necessary to promote appropriate SM by making sure that patients are given adequate information about the hazards posed by SM by encouraging them to seek information regarding the drug they intend to use-not from the Internet, but from physicians or pharmacists instead. Encouraging physicians or pharmacists to take part in this process is necessary to give clearer instructions to their patients, especially elderly patients, married patients, and those with a low educational level. This study shows a need for authorities to make existing laws regarding drugs more stringent; it should also encourage policymakers to be more responsive to ensure that people can adequately access health care.

\section{CONFLICTS OF INTEREST}

The authors declare they have no conflicts of interest.

\section{AUTHORS' CONTRIBUTION}

SA and SR contributed in study conceptualization. RKZ and HS contributed in data curation. BD, RKZ, HS and SB contributed in formal analysis; SA, AAH and SR contributed in funding acquisition. SA, SZ and AAH contributed in methodology. SA and SR contributed in project administration. SA, SR, SB and DK contributed in supervision. RKZ, HS, SA and BD contributed in writing (original draft) the manuscript. SA, BD, DK and JK contributed in writing (review and editing) the manuscript. 


\section{FUNDING}

This work was supported by the Doctoral School of Sciences and Technologies (EDST) at the Lebanese University (Hadat, Lebanon). It had no role in the study design, in the collection of data, in the analysis and interpretation of results, in the writing of the report, and in the decision to submit the article for publication. The views expressed are those of the authors and not necessarily those of the EDST.

\section{ABBREVIATIONS}

$\mathrm{CI}$, confidence interval; CP, community pharmacy; ENT, ear, nose and throat; GI, gastro-intestinal; NSAIDs, nonsteroidal antiinflammatory drugs; OR, odds ratio; OTC, over-the-counter; SM, self-medication; SPSS, Statistical Package for the Social Sciences; WHO, World Health Organization.

\section{REFERENCES}

[1] Schweim H, Ullmann M. Media influence on risk competence in self-medication and self-treatment. Ger Med Sci 2015;13;1-14.

[2] Khalifeh MM, Moore ND, Salameh PR. Self-medication misuse in the Middle East: a systematic literature review. Pharmacol Res Perspect 2017;5;e00323.

[3] World Health Organization. Guidelines for the regulatory assessment of medicinal products for use in self-medication. Geneva: World Health Organization; 2000. Available from: https://apps.who. int/iris/bitstream/handle/10665/66154/WHO_EDM_QSM_00.1_ eng.pdf? sequence $=1$ \&isAllowed $=y$ (accessed 09 May 2020).

[4] Loyola Filho AI, Lima-Costa MF, Uchôa E. Bambuí Project: a qualitative approach to self-medication. Cad Saúde Pública 2004;20;1661-9.

[5] Gualano MR, Bert F, Passi S, Stillo M, Galis V, Manzoli L, et al. Use of self-medication among adolescents: a systematic review and meta-analysis. Eur J Public Health 2015;25;444-50.

[6] Blenkinsopp A, Bradley C. Over the counter drugs: patients, society, and the increase in self-medication. BMJ 1996;312;629-32.

[7] Kamat VR, Nichter M. Pharmacies, self-medication and pharmaceutical marketing in Bombay, India. Soc Sci Med 1998;47;779-94.

[8] Mouhieddine TH, Olleik Z, Itani MM, Kawtharani S, Nassar H, Hassoun R, et al. Assessing the Lebanese population for their knowledge, attitude and practices of antibiotic usage. J Infect Public Health 2015;8;20-31.

[9] Al-Ramahi R. Patterns and attitudes of self-medication practices and possible role of community pharmacists in Palestine. Int J Clin Pharmacol Ther 2013;51;562-7.

[10] Asseray F, Ballereau F, Tombert-Paviot B, Bouget J, Foucher N, Renaud B, et al. Frequency and severity of adverse drug reactions due to self-medication: a cross-sectional multicentre survey in emergency departments. Drug Saf 2013;36;1159-68.

[11] Fuentes Albarrán K, Villa Zapata L. Analysis and quantification of self-medication patterns of customers in community pharmacies in southern Chile. Pharm World Sci 2008;30;863-8.

[12] Nunes de Melo M, Madureira B, Nunes Ferreira AP, Mendes Z, Miranda Ada C, Martins AP. Prevalence of self-medication in rural areas of Portugal. Pharm World Sci 2006;28;19-25.
[13] Baig S. Self-medication practices. Prof Med J 2012;19;513-21.

[14] Alghanim SA. Self-medication practice among patients in a public health care system. East Mediterr Health J 2011;17;409-16.

[15] Badiger S, Kundapur R, Jain A, Kumar A, Pattanshetty S, Thakolkaran N, et al. Self-medication patterns among medical students in South India. Australas Med J 2012;5;217-20.

[16] Heisler M, Langa KM, Eby EL, Fendrick AM, Kabeto MU, Piette JD. The health effects of restricting prescription medication use because of cost. Med Care 2004;42;626-34.

[17] Stasio MJ, Curry K, Sutton-Skinner KM, Glassman DM. Overthe-counter medication and herbal or dietary supplement use in college: dose frequency and relationship to self-reported distress. J Am Coll Health 2008;56;535-48.

[18] Farah R, Lahoud N, Salameh P, Saleh N. Antibiotic dispensation by Lebanese pharmacists: a comparison of higher and lower socio-economic levels. J Infect Public Health 2015;8;37-46.

[19] Carrasco-Garrido P, Jiménez-García R, Barrera VH, Gil de Miguel A. Predictive factors of self-medicated drug use among the Spanish adult population. Pharmacoepidemiol Drug Saf 2008;17;193-9.

[20] Figueiras A, Caamaño F, Gestal-Otero JJ. Sociodemographic factors related to self-medication in Spain. Eur J Epidemiol $2000 ; 16 ; 19-26$.

[21] Mehuys E, Van Bortel L, De Bolle L, Van Tongelen I, Remon JP, De Looze D. Self-medication of upper gastrointestinal symptoms: a community pharmacy study. Ann Pharmacother 2009;43;890-8.

[22] Kulkarni PK, Khan M, Chandrasekhar A. Self medication practices among urban slum dwellers in south Indian city. Int J Pharm Bio Sci 2012;3;81-7.

[23] Auta A, Omale S, Folorunsho TJ, David S, Banwat SB. Medicine vendors: self-medication practices and medicine knowledge. N Am J Med Sci 2012;4;24-8.

[24] Wilcox CM, Cryer B, Triadafilopoulos G. Patterns of use and public perception of over-the-counter pain relievers: focus on nonsteroidal antiinflammatory drugs. J Rheumatol 2005;32;2218-24.

[25] Richy F, Bruyere O, Ethgen O, Rabenda V, Bouvenot G, Audran $\mathrm{M}$, et al. Time dependent risk of gastrointestinal complications induced by non-steroidal anti-inflammatory drug use: a consensus statement using a meta-analytic approach. Ann Rheum Dis 2004;63;759-66.

[26] Verma RK, Mohan L, Pandey M. Evaluation of self medication among professional students in North India: proper statutory drug control must be implemented. Asian J Pharm Clin Res 2010;3;60-4.

[27] Hayran O, Karavus M, Aksayan S. Help-seeking behavior and self-medication of a population in an urban area in Turkey: cross sectional study. Croat Med J 2000;41;327-32.

[28] Sallam SA, Khallafallah NM, Ibrahim NK, Okasha AO. Pharmacoepidemiological study of self-medication in adults attending pharmacies in Alexandria, Egypt. East Mediterr Health J 2009;15;683-91.

[29] Moraes AC, Delaporte TR, Molena-Fernandes CA, Falcão MC. Factors associated with medicine use and self-medication are different in adolescents. Clinics (São Paulo) 2011;66;1149-55.

[30] Drug Utilization Research Group, Latin America. Multicenter study on self-medication and self-prescription in six Latin American countries. Clin Pharmacol Ther 1997;61;488-93. 
[31] Farah SM, Chowdhury ABMA, Hossain MK, Mohammadnezhad M, Russell K. Exploring the knowledge, attitude and practices towards use of unprescribed drugs among adults of a selected city of Somaliland. J Adv Med Pharm Sci 2018;19;1-7.

[32] Cindy LK, Maxwell HW, Clarke M. A survey on the use of self-medication over a period of two weeks. Hong Kong J 1989;11;371-5.

[33] Närhi U, Helakorpi S. Analgesic users' sources of medicine information. Int J Pharm Pract 2007;15;251-3.

[34] Davidow LW. Self-care and nonprescription pharmacotherapy. In: Berardi RR, Ferreri SP, Hume AL, et al., editors. Handbook of nonprescription drugs: an interactive approach to self care. 16th ed. Washington DC: American Pharmacists Association; 2009, pp. 13-14.

[35] World Health Organization. The role of the pharmacist in self care and self medication. Geneva: World Health Organization; 2019. Available from: http://apps.who.int/medicinedocs/pdf/ whozip32e/ whozip32e.pdf (accessed 16 February 2019).

[36] Feikin DR, Audi A, Olack B, Bigogo GM, Polyak C, Burke H, et al. Evaluation of the optimal recall period for disease symptoms in home-based morbidity surveillance in rural and urban Kenya. Int J Epidemiol 2010;39;450-8. 